\author{
اثر فاصله قطرهجكانها بر گرفتخى فيزيكى نوارهاى آبيارى قطرهاى \\ جنور عبدى و يرويز فتحى *

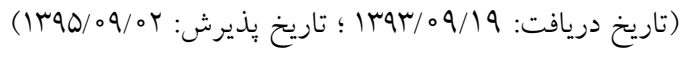

جكيده

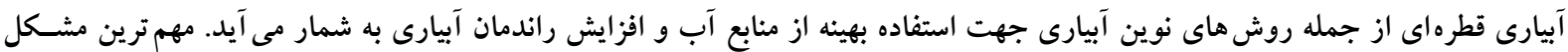

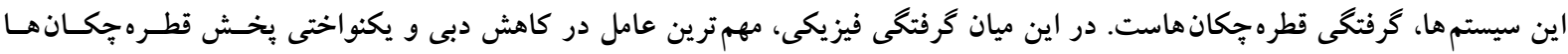

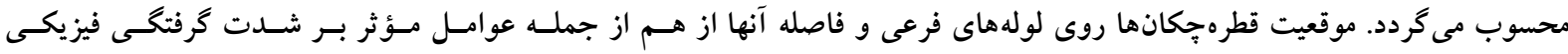

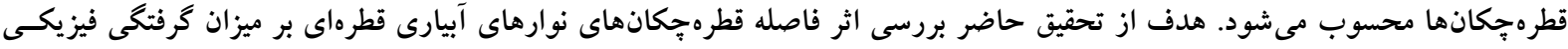

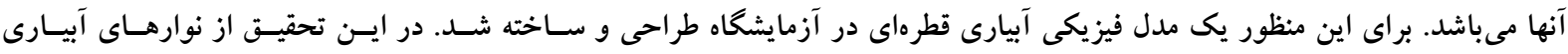

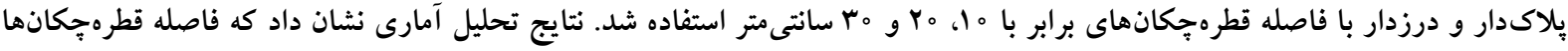

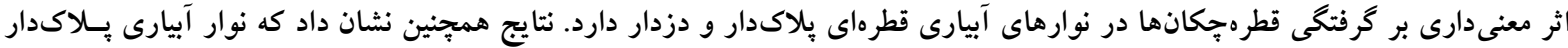

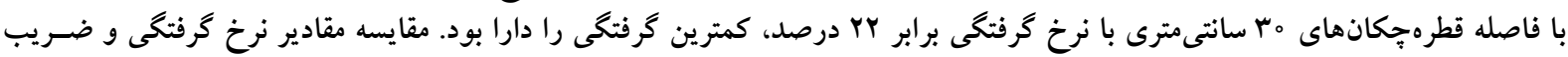

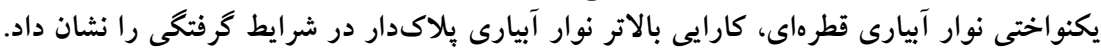

وازههاى كليدى: آبيارى قطرهاى، نوار آيارى، گرفتخى فيزيكى، فاصله قطرهجكان 
نتايج اين تحقيق نشان داد كه ورود مواد فيزيكى بـهـويـزه ذرات

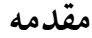

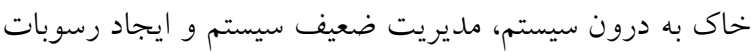

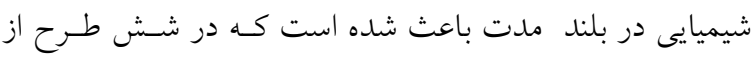
طرحهاى ارزيابى شده، راندمان سيستم ضعيف تا متوسط باشد.

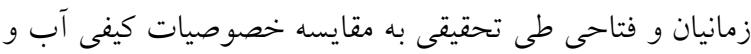

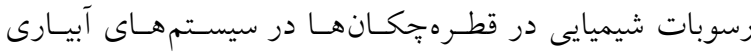

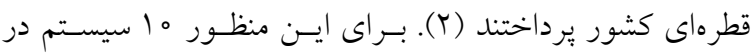

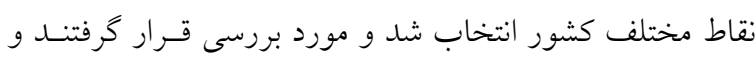

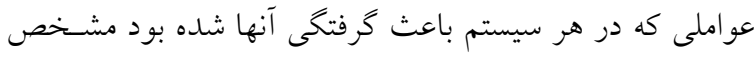

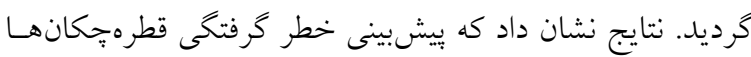

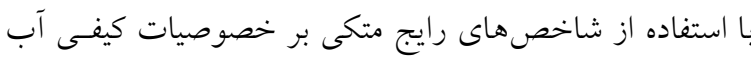

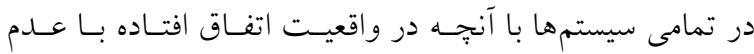
قطعيت بالايى همـراه بـود. در 90 درصــ از مـوارد بــيشبينى

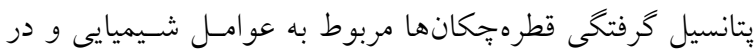

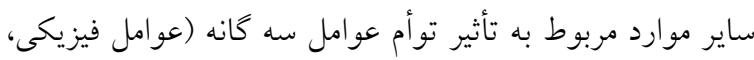

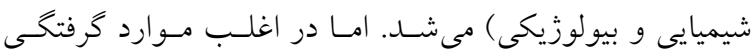

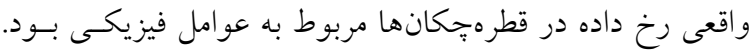

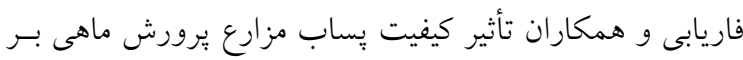

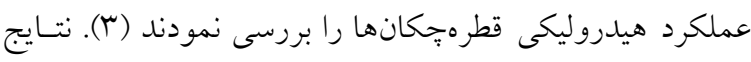

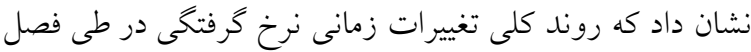

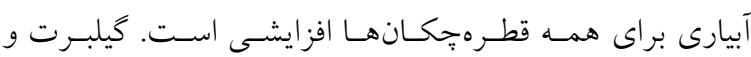

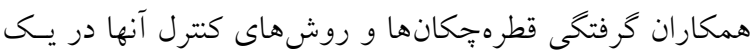

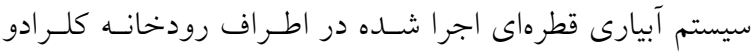

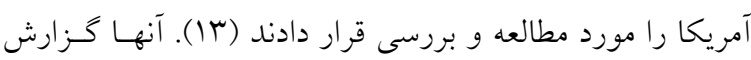

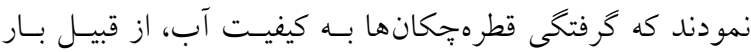
رسوبات معلق، تركيبات شيميايى و فعاليتهاى بيولـوزيكى در

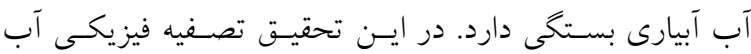

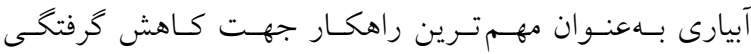

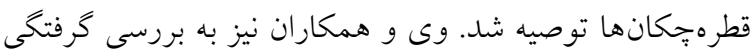

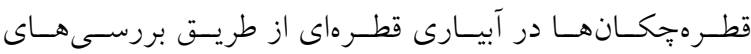

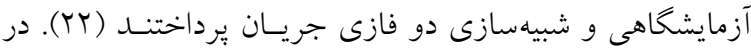

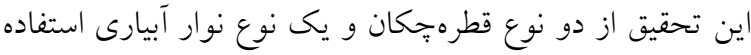
رشد روزافزون جمعيت دنيا و به دنبال آن افزايش تقاضا بـراى توليــد محصـولات كشــاورزى و مــواد غــذايى از يـك سـو و

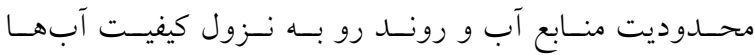
بهخصوص در منـاطق خشـى و نيمهـخشـى از سـوى ديخـر،

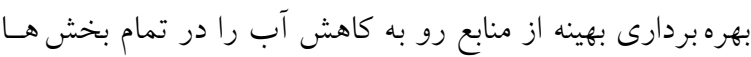

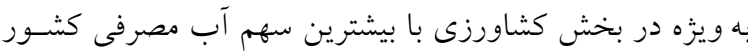

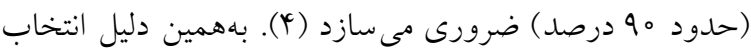
روش هاى مناسب توزيع آب آبيارى در سطح مـزارع و باغـات جهت مصرف بهينه آب، يكى از راهكارهاى مـديريتى مـؤثر در

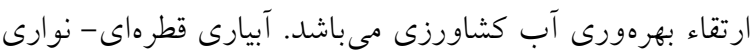

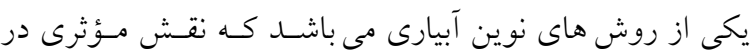

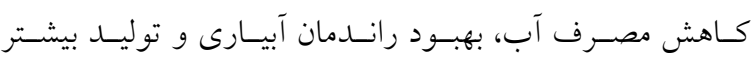

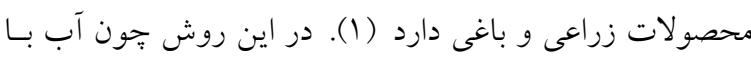

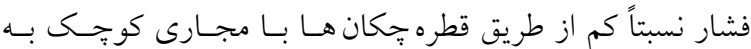

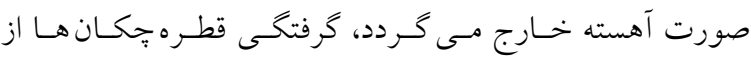

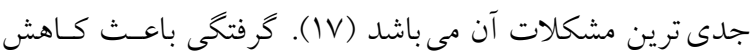

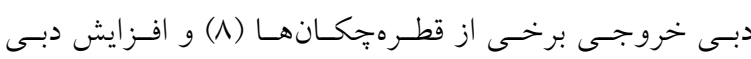

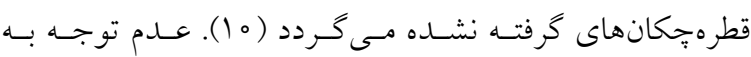

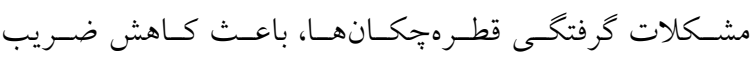

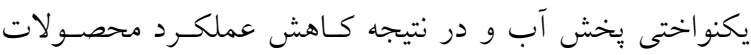

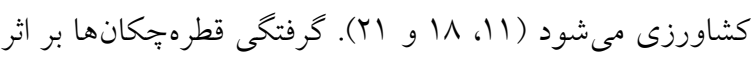

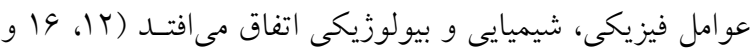

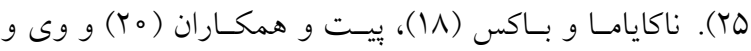

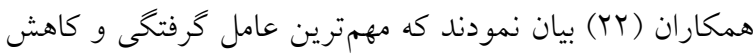

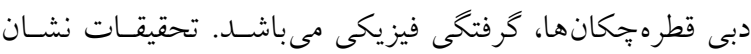

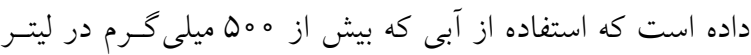
ذرات جامد معلق دارد، سبب مسدود شدن خروجىها مى گردد.

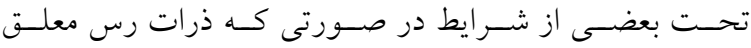

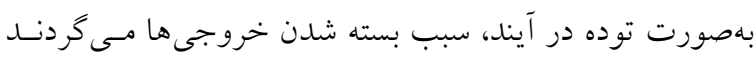

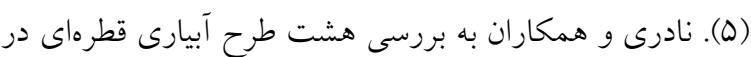

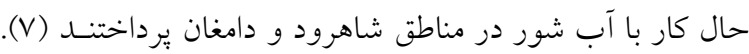




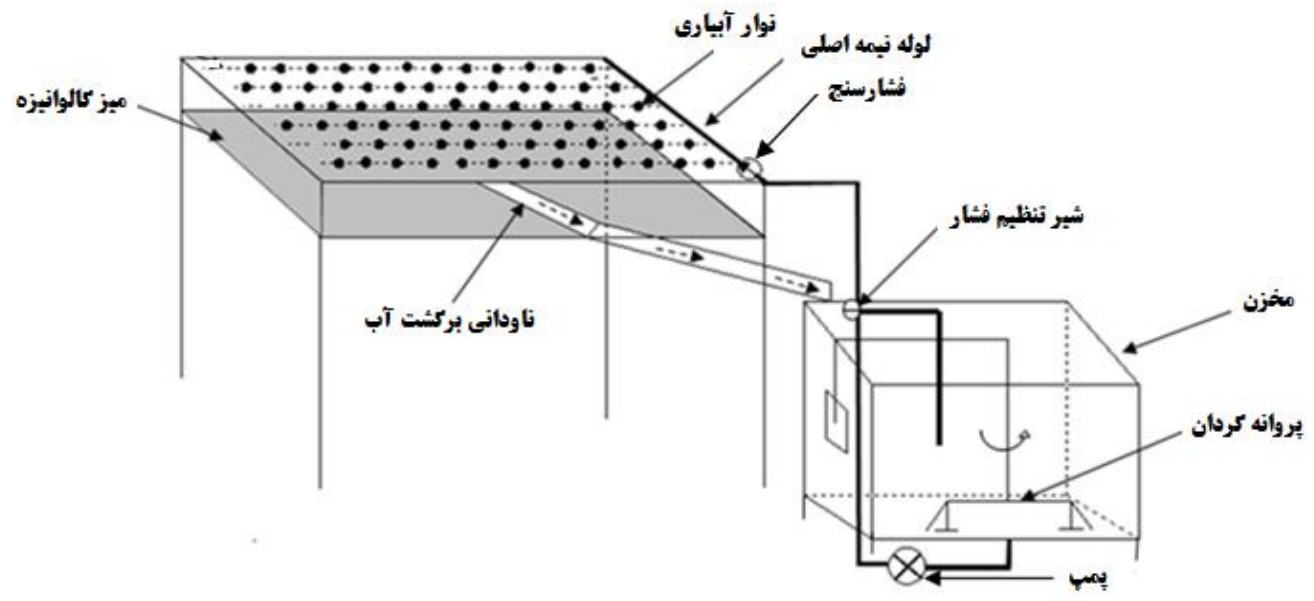

شكل 1. نقشه شماتيك از مدل فيزيكى آبيارى قطرهاى

نوارهاى آبيارى بر عملكرد عدم گرفتّى فيزيكسى نـوار آبيـارى

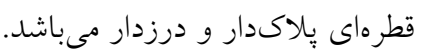

\section{مواد و روشها - ماد}

بمنظور بررسى اثر فواصل مختلف قطرهجانكانهاى نوار آبيـارى

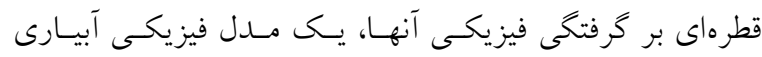

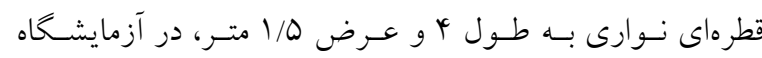
تحقيقات آب و خاك دانشخاه كردستان، طراحى، نصب و و اجـرا

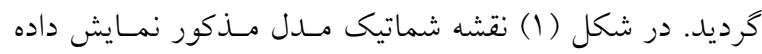

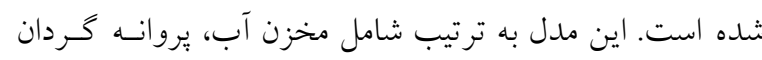

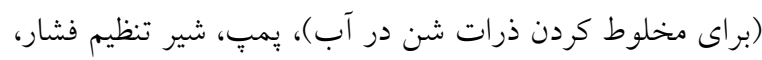

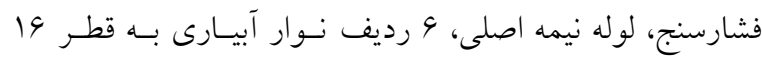

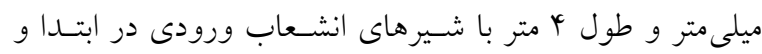

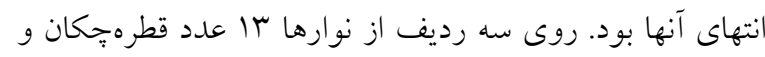

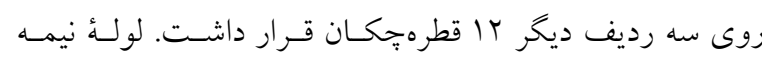

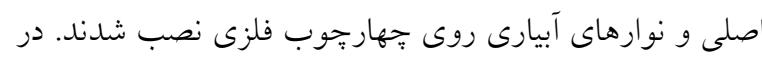

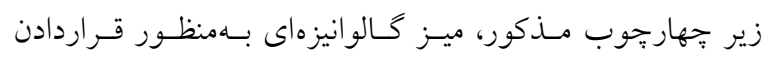

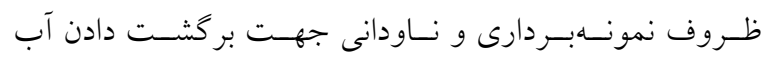

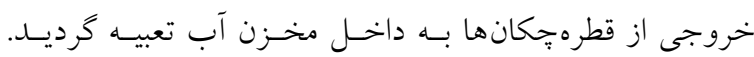

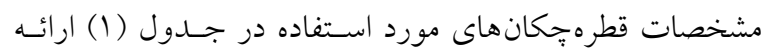
شده است. آزمايش در هشت فاز مه دقيقهاى مطابق استاندارد
شـد. نتـايج شـبيهسـازى نشـان دادكسه ذرات جامسـ در داخـل قطرهجكان با جريان متلاطم حركت كرده و بدون تسهنشينى از

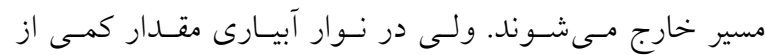
رسوبات در لبههاى خروجى مسير به هم جسبـيده و تسهنشسين

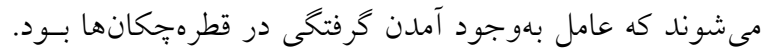

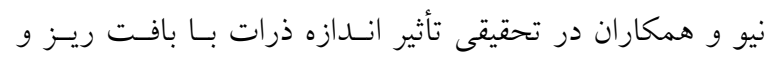

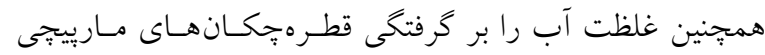

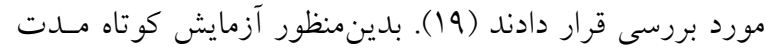

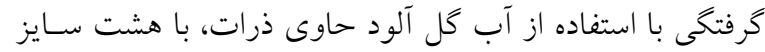
مختلف (كمتر از //ه ميلىمتـر) صـورت كرفـت. ذرات مـورد استفاده در اين مطالعه، شامل شن ريز، سيلت و رس بود. نتسايج نشان داد كه براى ذرات با قطر كوجگكتر از / / ميلىمتر، غلظت

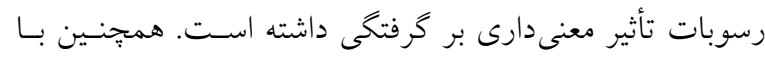

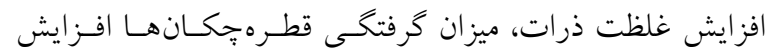

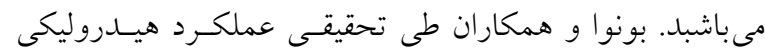

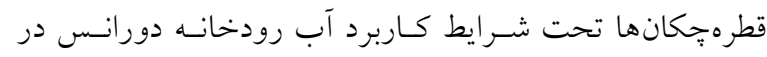
جنوب فرانسه و تأثير ورود تدريجى رسـوبات و و سـاير عوامـل

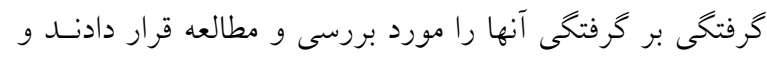

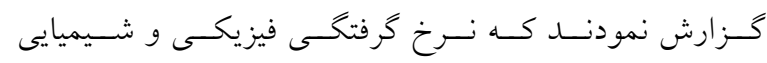

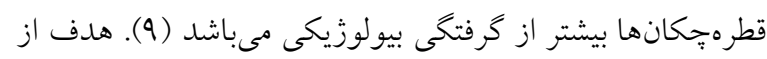

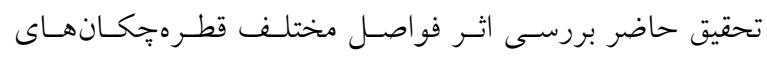


نشريه علوم آب و خاك (علوم و فنون كثاورزى و منابع طبيعى) / سال بيست و يك / شماره سه/ باييز وجس|

\begin{tabular}{|c|c|c|c|c|c|}
\hline \multicolumn{6}{|c|}{ جدول ا. مشخصات نوارهاى آبيارى قطرهاى مورد استفاده } \\
\hline ضريب تغييرات & فشار اسمى & (ميكرون) & $\begin{array}{c}\text { فاصله قطرهج:جانها } \\
\text { (cm) }\end{array}$ & $\begin{array}{c}\text { دبى اسمى (lit/h) } \\
\text { (lit) }\end{array}$ & نوع نوار آبيارى \\
\hline$r / \Lambda$ & 10 & roo & r。 & r & \\
\hline$\varphi / 0$ & 10 & roo & $r_{0}$ & r & 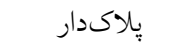 \\
\hline $4 / r$ & 10 & roo & 1. & r & \\
\hline $4 / 9$ & 10 & IVD & r。 & r & \\
\hline $4 / 9$ & 1. & IVQ & $r_{0}$ & r & حرزدار \\
\hline$\varphi / 0$ & 10 & IVD & 10 & r & \\
\hline
\end{tabular}

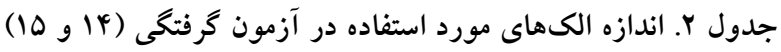

\begin{tabular}{|c|c|c|}
\hline غلظت ذرات (ميلى گرم در ليتر) & قطر منافذ الكها (ميكرومتر) & فازهاى آزمايش \\
\hline ro० & 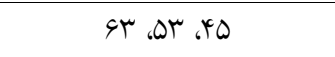 & فاز 1 \\
\hline rQ。 & VD & 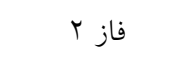 \\
\hline ro。 & $90, V \Delta, g r$ & 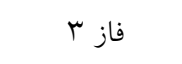 \\
\hline ro。 & $109 ، 90,60$ & 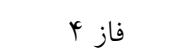 \\
\hline ro. & $150,109 ، 90$ & فاز هـ \\
\hline ro。 & $1 \Lambda \circ, 100,1 T 0$ & فاز \\
\hline TQ。 & TIT، IN०، 100 & 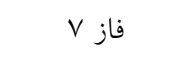 \\
\hline ro。 & TQ० & فاز \\
\hline
\end{tabular}

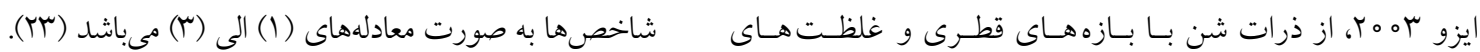

$C_{r}=100\left|-\frac{\bar{q}}{q_{V}}\right|$

$\overline{\mathrm{q}}=\left(\sum_{\mathrm{i}=1}^{\mathrm{n}} \mathrm{q}_{\mathrm{i}}\right) / \mathrm{n}$

$C_{u}=100\left(1-\frac{\sum_{i=1}^{n}\left|q_{i}-\bar{q}\right|}{\sum_{i=1}^{n} q_{i}}\right)$

كه در آن،

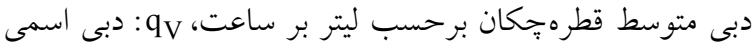

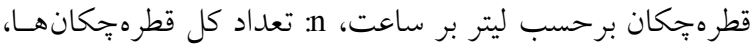

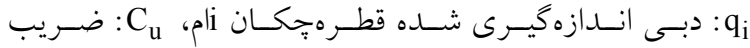
يكنواختى كريستيانسن مى باشد.

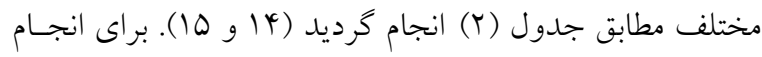

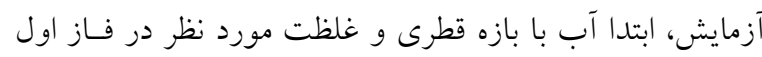

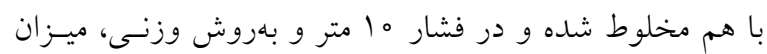

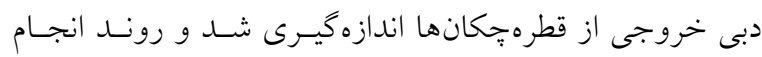

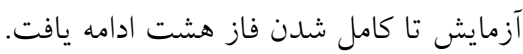

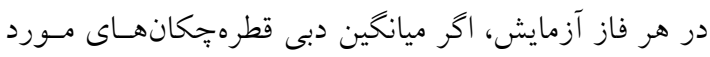

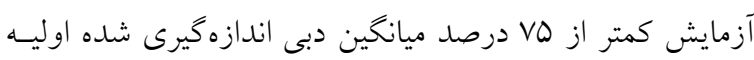

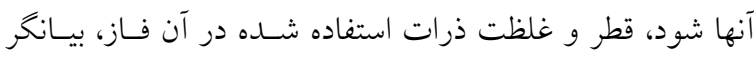

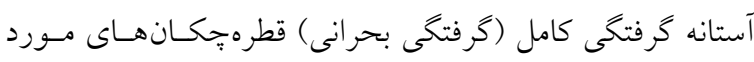
مطالعه مىباشد (4 (1).

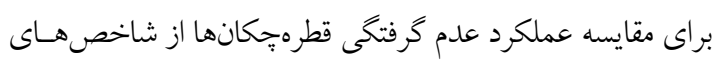

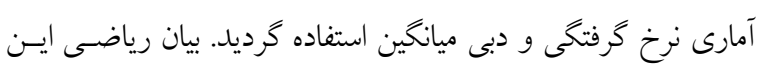


اثر فاصله قطرهجكانها بر كرفتخى فيزيكى نوارهاى آبيارى قطرهاى

جدولr. مقادير دبى ميانگين قطرهجِانها برحسب ليتر بر ساعت در فازهاى مختلف آزمايش

\begin{tabular}{|c|c|c|c|c|c|c|c|c|c|}
\hline فاز & 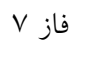 & فاز 9 & فاز هـ & فاز باز & فاز r & 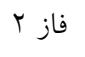 & فاز 1 & فاصله قطره:جكانها & \\
\hline $1 / T r$ & $1 / \pi \circ$ & $1 / \Gamma_{\Lambda}$ & $1 / 49$ & $1 / 90$ & $1 / V_{0}$ & $1 / \mathrm{WV}$ & I/AV & ها سانتىمتر & \\
\hline 1/or & $1 / \Delta V$ & $1 / 94$ & $I N T$ & $1 / \mathrm{VA}$ & I/AV & $1 / 91$ & $1 / 90$ & Tlo rov متر & نوار بِاكددار \\
\hline $1 / \Delta \infty$ & $1 / N 1$ & $1 / V^{4}$ & $1 / \mathrm{VA}$ & $1 / 11$ & $1 / 19$ & $1 / 91$ & $1 / 90$ & مبانتى متر & \\
\hline $1 / 09$ & $1 / 14$ & $1 / T r$ & $1 / \pi \circ$ & $1 / 41$ & $1 / \Delta \psi$ & $1 / \Delta V$ & $1 / 90$ & ه ا سانتى متر & \\
\hline $1 / T V$ & $1 / 4 \wedge$ & $1 / \Delta 0$ & $1 / 90$ & $1 / 94$ & $1 / V_{0}$ & $1 / V 9$ & $1 / 91$ & مانتى ro متر & نوار درزدار \\
\hline$|/ 4|$ & $1 / Q 4$ & $1 / \Delta V$ & $1 / 94^{\circ}$ & $1 / 91$ & $1 / N T$ & $1 / N K$ & $1 / \Lambda r$ & مr سانتى متر & \\
\hline
\end{tabular}

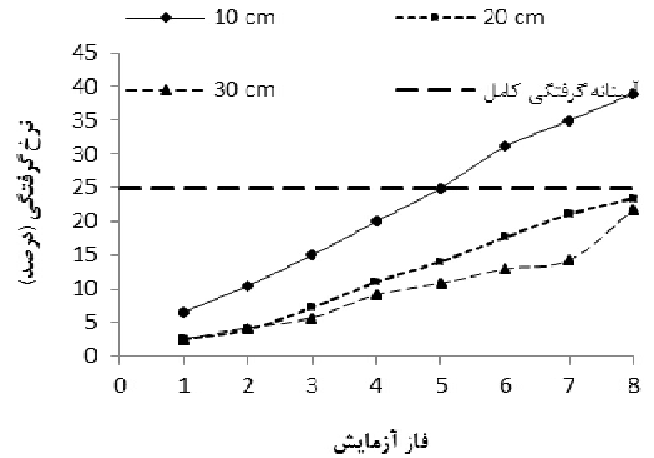

شكل r. مقادير نرخ گرفتخى نوارهاى آبيارى بِلاكدار با فواصل

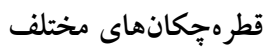

فو اصل قطرهجانهان متفاوت و در فازهاى مختلف آزمايش به

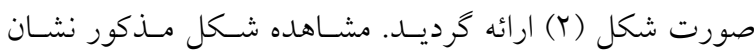

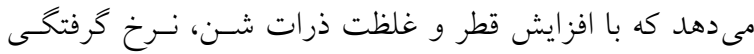

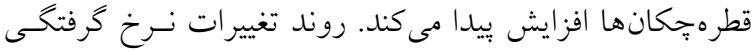

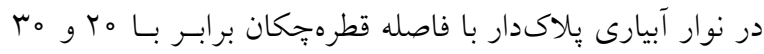

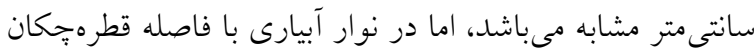

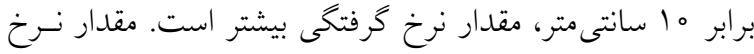

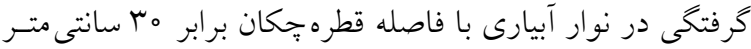
كمتر از دو نوع ديخر بوده به طورى كه تا فاز V آزمايش، مقـــدار

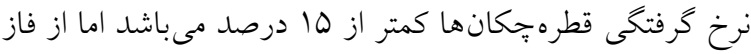

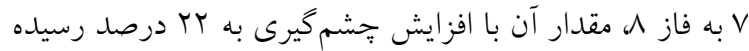

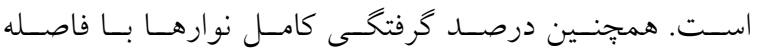

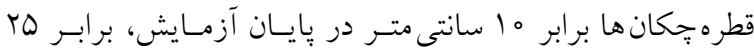

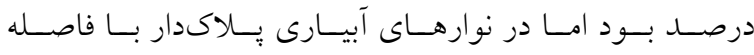

همجنين بهمنظور بررسى تحليل آمارى شاخص هاى فوقالـذكر از نرمافزار R و همجنين شاخص خطاى معيار استفاده گرديد.

$s d=\sqrt{\frac{\sum_{1}^{n}\left(x_{i}-\bar{x}\right)^{r}}{n-1}}$

$\mathrm{SE}=\frac{\mathrm{sd}}{\sqrt{\mathrm{n}}}$

كه در آن sd انحر اف از معيار شاخص مورد نظـر، X

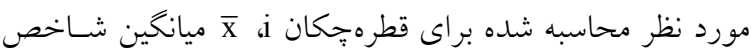
مورد نظر و SE خطاى معيار شاخص مورد نظر مىباشد.

\section{نتايج و بحث}

مقدار ميانگين دبى قطرهجِكانها در فازهاى مختلف آزمسون، در جدول (r) نمايش داده شده است. مشـاهده جــدول (r) نشـان

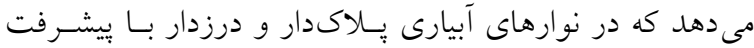

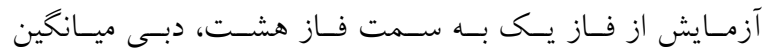
قطرهجكانها كاهش يافته است. در هر همــه نوارهـاى آبيـارى مورد مطالعه، بيشترين دبى قطرهجكانها در فاز اول و كمتـرين

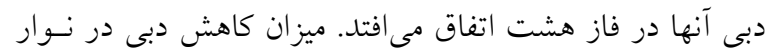

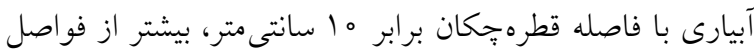
ديخر است. مقايسه نتايج جدول (T) براى دبى ميانخين نوارهاى

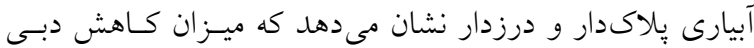
ميانكين در نوار آبيارى جـالاكدار كمتـــ از نـوار آبيـارى درزدار مىباشد. روند تغييرات نرخ كرفتخى نـوارهـاى آبيـارى يـلاكدار بـا 


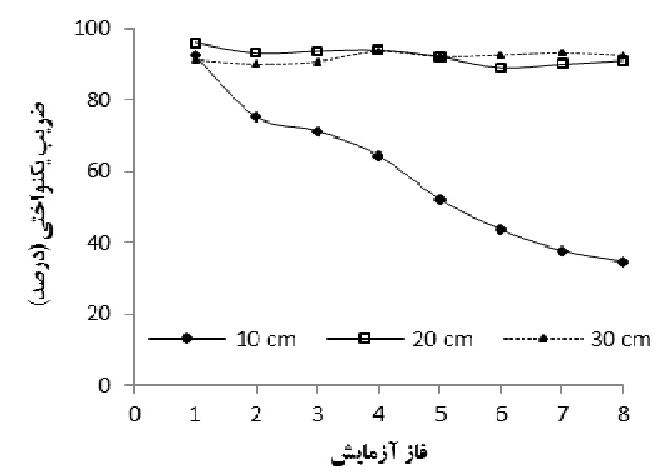

شكل †. ضريب يكنواختى كريستيانسن نوار آبيارى بِاكدار با فواصل مختلف

بهصورت توأم مشاهده گرديد. در نوار آبيـارى مـذكور، درصـــ

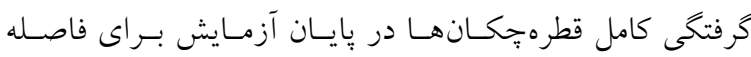

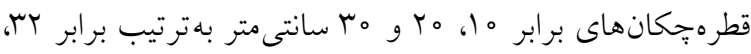

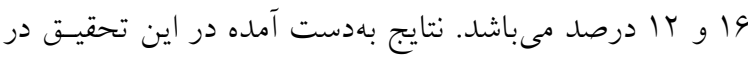

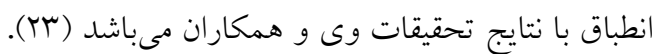

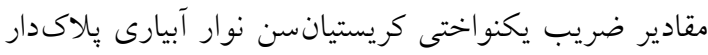

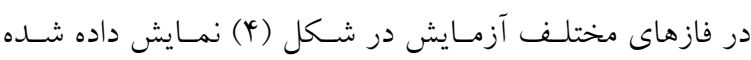

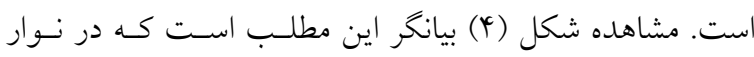

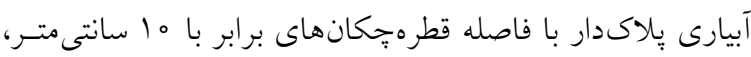

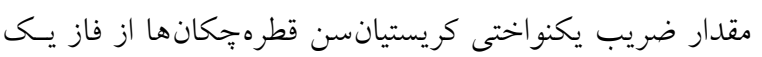

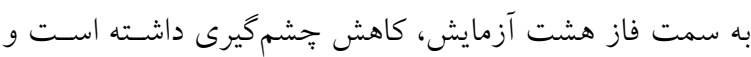

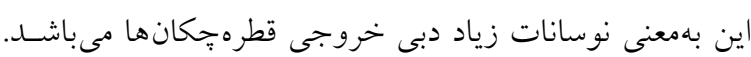

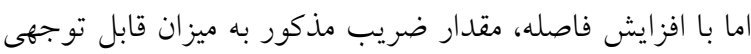

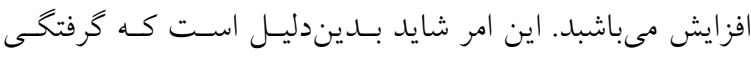

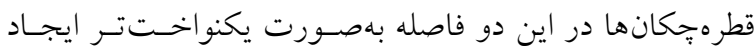

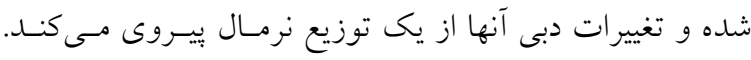

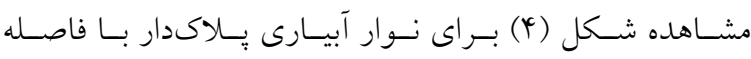

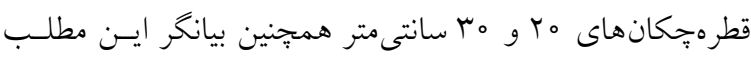

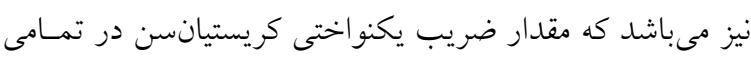

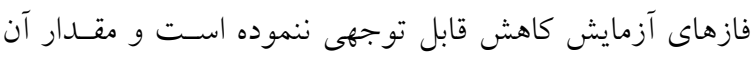

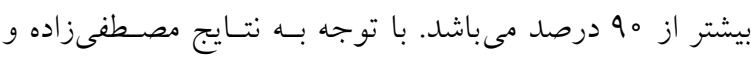

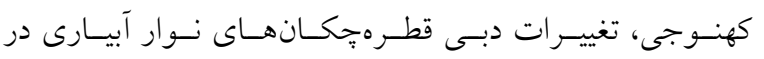

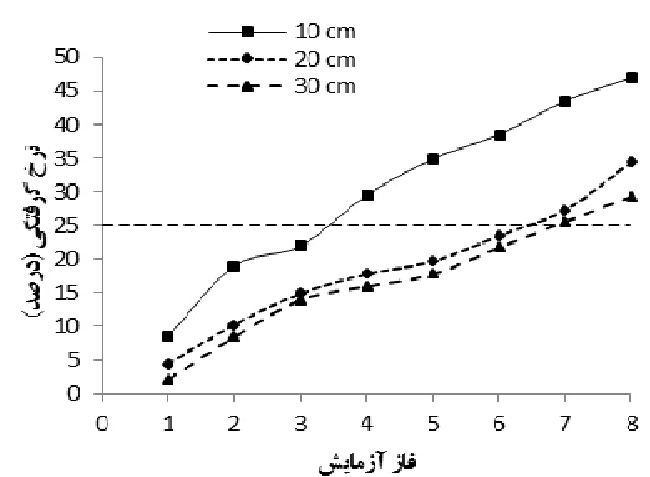

شكل r. مقادير نرخ كَفتخى نوارهاى آبيارى درزدار با فواصل

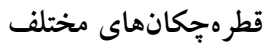

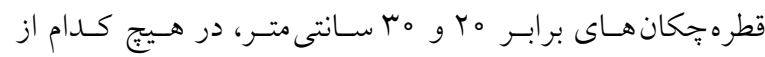

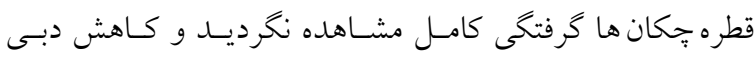

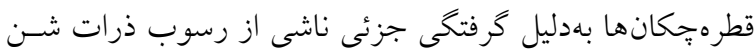

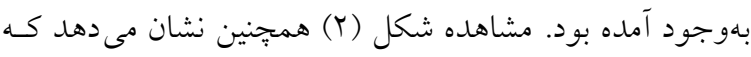

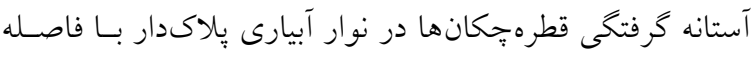

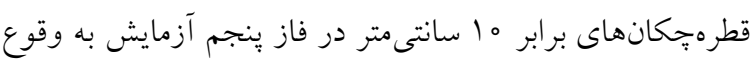

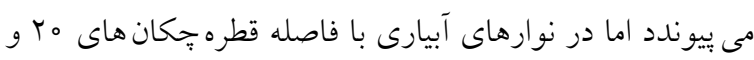

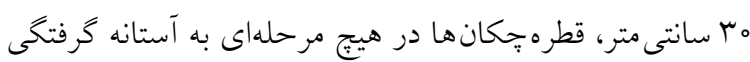
كامل نرسيدهاند. در شكل (r) مقادير نرخ كرفتكى نـوار آبيـارى درزدار بـاــا

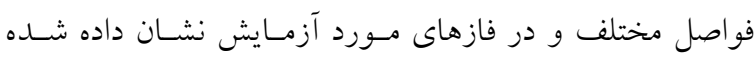
است. مشاهده شكل (r) نشان مى دهد كه در نوار آبيارى درزدار

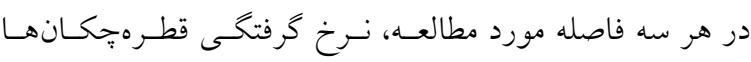

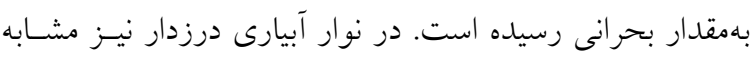

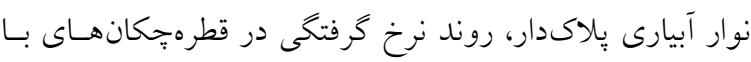

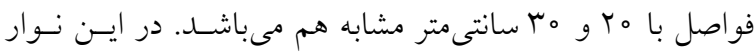

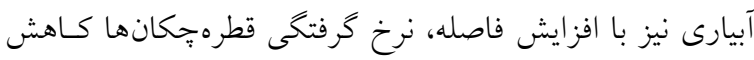

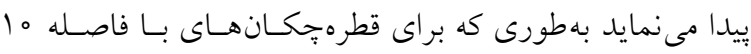

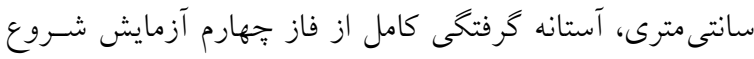

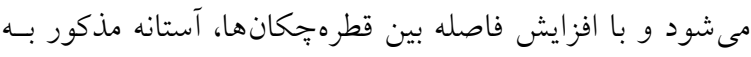

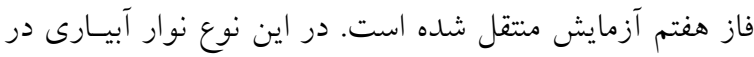

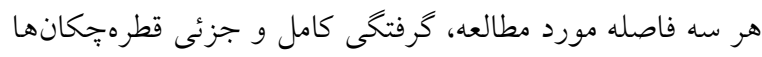




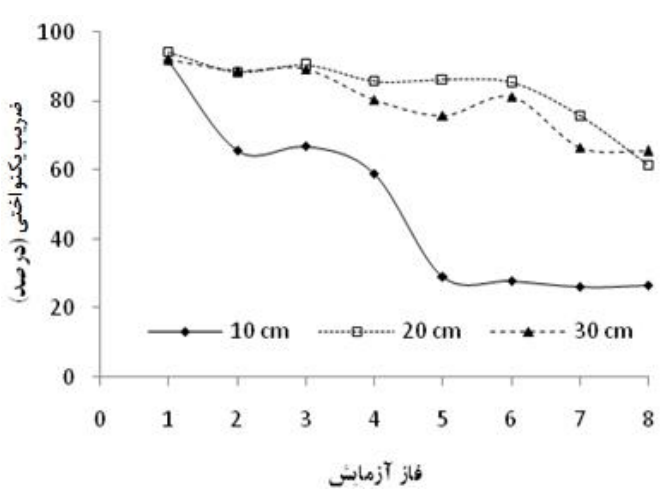

شكل ه. ضريب يكنواختى كريستيانسن نوار آبيارى درزدار با فواصل مختلف

جدول f. تجزيه واريانس اثر فاصله و نوع قطرهجكان بر شاخصهاى مورد مطالعه

\begin{tabular}{|c|c|c|c|c|}
\hline & & ميانخين مربعات & درجه & منابع تغيير \\
\hline ضريب يكنواختى & نرخ كرفتخى & دبى ميانخين & آزادى & \\
\hline r৭९N/r** & $01 \Lambda / V^{* *}$ & $\circ / 190^{* *}$ & r & فاصله \\
\hline$r \notin 99 / 1^{* *}$ & M & - / r r $Q^{* *}$ & 1 & نوع نوار آبيارى \\
\hline $\mid \wedge \circ / \wedge r^{* *}$ & $\Delta / \Lambda \circ V^{* *}$ & $\circ / \circ \circ \Delta^{* *}$ & r & فاصله ×نوع نوار آبيارى \\
\hline.$/ 91$ HY $^{-}$ & $0 / 1 M y$ & $0 / 0001$ & Ir & خطا \\
\hline
\end{tabular}

در جدول (4) نتايج تجزيه واريانس اثر فاصسله، نــوع نـوار

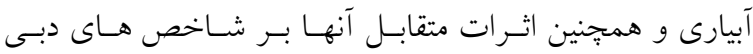
ميانخين، نرخ گرفتخى و ضريب يكنو اختى كريستيان سـن ارائسه شده است. مشاهده جدول مذكور نشان مى دهد كه اثـر فاصـله، نوع نوار آبيارى و اثرات متقابل آنها بر هر سه شـاخص مـذكور در سطح آمارى يك درصدمعنى دارى مىباشد. در شكل هاى (Y) و (V) نتايج حاصل از مقايسه ميانگين اثر

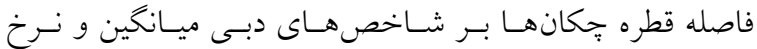
كرفتخى نوار آبيارى هاى مورد مطالعه در انتهاى آزمـايش (فـاز هشت) نشان داده شده است. در اين تحقيق از شاخص خطـاى اسـتاندارد بــراى مقايسـه ميـانخين اسـتفاده گرديـــــ مشــاهده شكلهاى مذكور بيانكر اين مطلب است كه تفاوت معنسىدارى

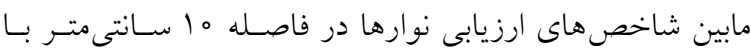
ساير فو اصل قطره جُكانها وجود دارد. اما اختلاف معنسى دارى ما بين شـاخصهــاى مـذكور در نــوار آبيـارىهــاى بـا فاصـله
تحقيق حاضر از يك توزيع نرمال بيروى مى نمايد (9). اين امر نشان مىدهد كه در اين نوارها، كرفتخى فيزيكىى، تـأثير قابـل توجهى بر ضريب يكنواختى كريستيانسن ندارد. مقادير ضريب يكنواختى كريستيانسن نوار آبيارى قطـرهاى درزدار بهصورت شكل (ه) نمـايش داده شــده اسـت. مشـاهده شكل مذكور نشان مى دهد كـهـ در نوارهـاى آبيـارى بـا فاصـله

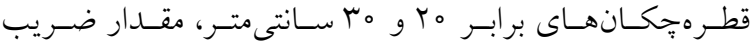

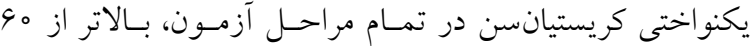
درصد مىباشد. بيشترين و كمتـرين مقــار ضـريب يكنـواختى

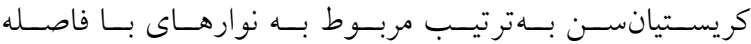

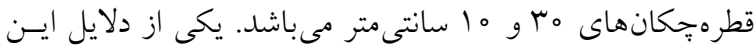
امر كـاهش درصـد كرفتخـى كامـل در فواصـل بزركتــ قطـره جكانهاى مىباشد. وو و همكاران نيز گزارش نمودند كه فاصله

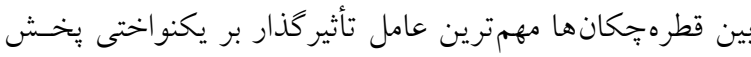

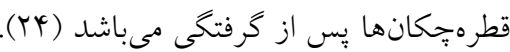




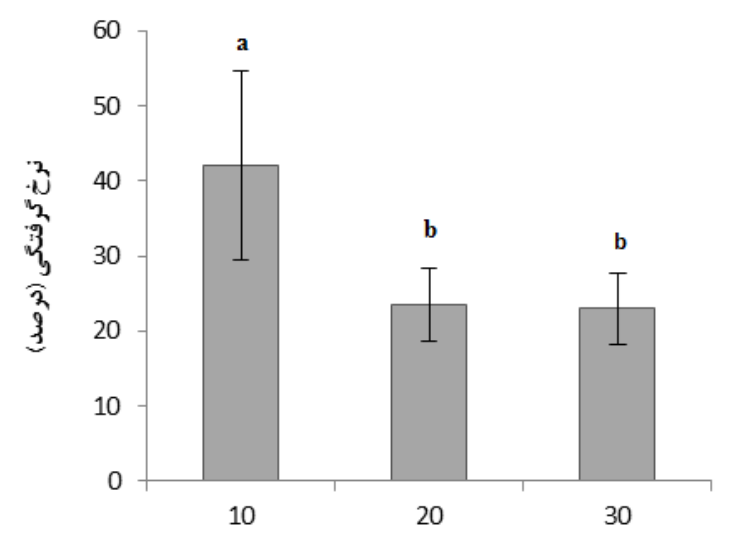

فاصله بين قطره جָكان ها (cm)

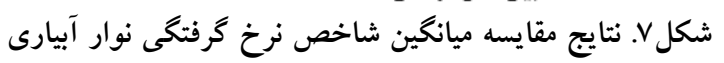
يلاكدار با فواصل قطرهجِكانهاى مختلف

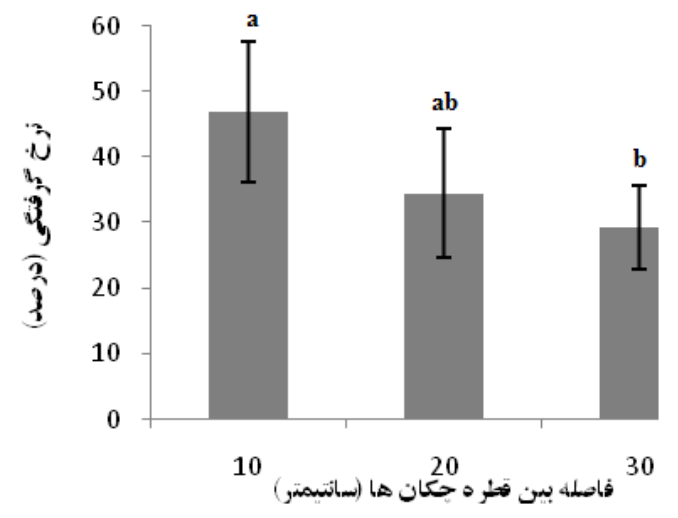

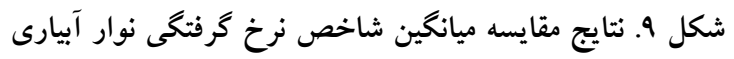

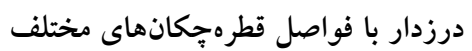

\section{نتيجه گيرى}

نتايج حاصل از ايسن بــزوهش نشـان مسىدهـد كـه فاصـله بـين

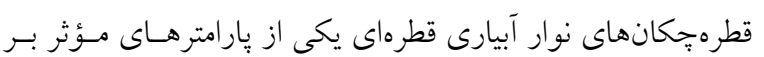
كاهش كرفتكى فيزيكى آنها مىباشد. در ايسن تحقيـق نـوارهـاى آبيارى با فاصله قطرهج جانهاى برابر هب و ه ا سانتى متر بهترتيب داراى بهترين و بدترين عملكرد عدم گرفتخى بودند. مقادير نـرخ

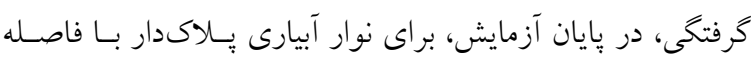

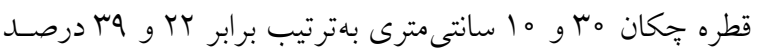
و براى نوار آبيارى درزدار، مقـادير ايسن شـاخص بــراى فواصـل

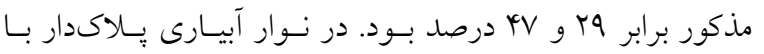

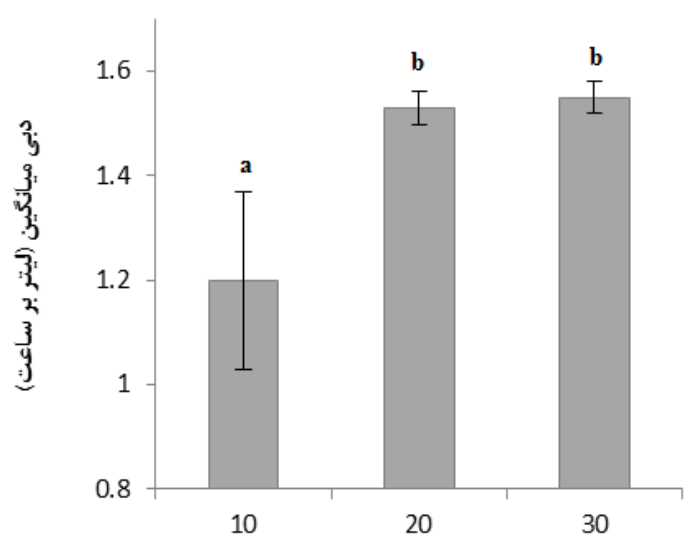

فاصله بين قطره جحكان ها (cm)

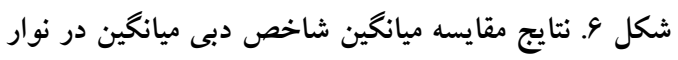

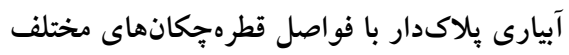

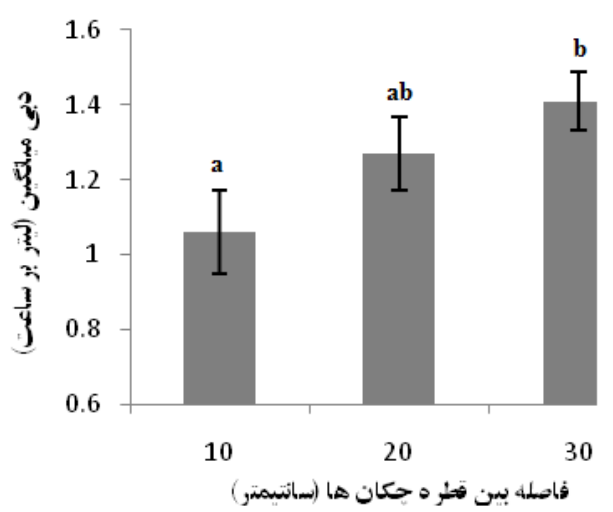

شكل ^ـ نتايج مقايسه ميانخين شاخص دبى ميانخين نوار آبيارى درزدار با فواصل قطرهجِانهاى مختلف

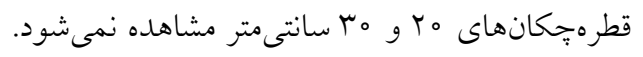
نتايج مقايسـه ميـانخين اتـر فاصـله قطـره جكــانهـا بـر شاخص هاى مذكور در نوار آبيـارى درزدار نيـز بـه صـورت

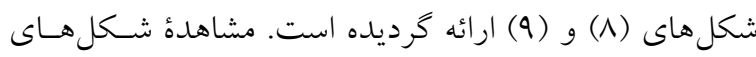
مذكور نشـان مسىدهــ كـه در نوارهـاى آبيـارى بـا فاصـله قطرهجّانهاى ه 1 و •r سانتى متر، اختلاف معنى دارى مابين شاخص هاى دبى ميانخين و نـرخ كرفتخـى وجـود دارد، امـا مقادير شاخص هاى مذكور در نوار آبيارى درزدار بـا فاصـله قطره:جان ه r سانتى متر اختلاف معنى دارى با ساير فاصله ها

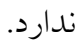




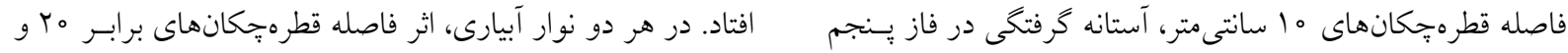

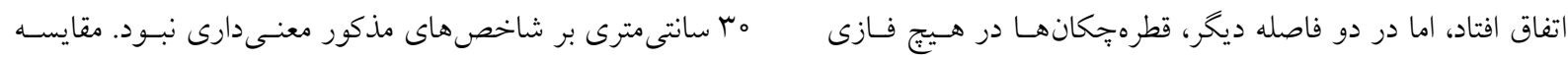

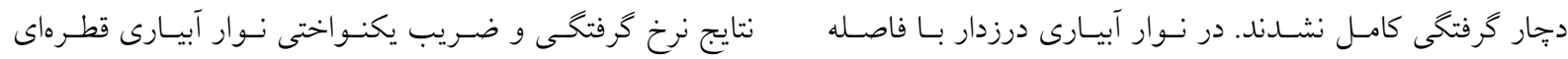

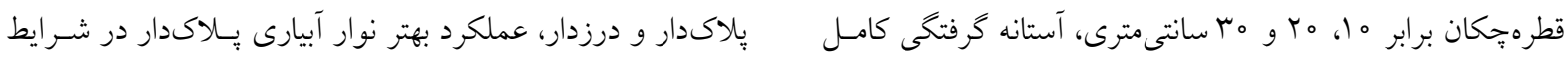

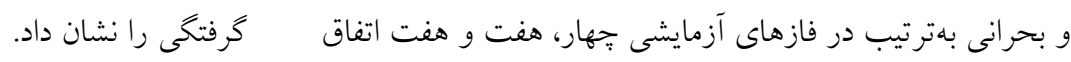

\section{منابع مورد استفاده}

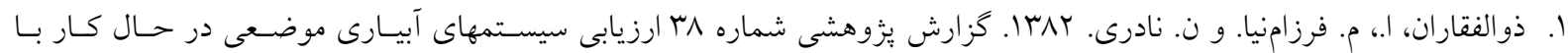

$$
\text { آب هاى نامتعارف. مؤسسه تحقيقات فنى و مهندسى كشاورزى. }
$$

ז. زمانيان، م. و ر. فتاحى. سوبا. مقايسه خصوصيات كيفى آب و رسوبات شيميايى عامل انسداد قطرهجهانها در سامانهاى آبيارى

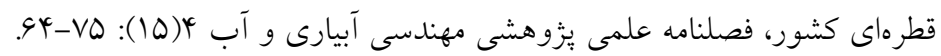

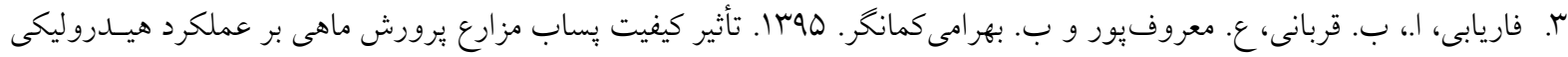

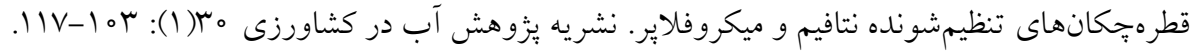

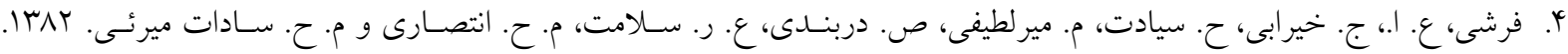

مليريت آب آبيارى در مزرعه، انتشارات كميته ملى آبيارى و زهكشى ايران، شماره انتشار لو، تهران.

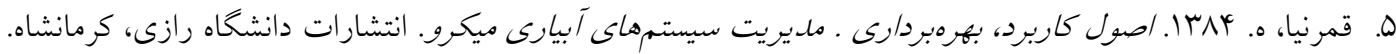

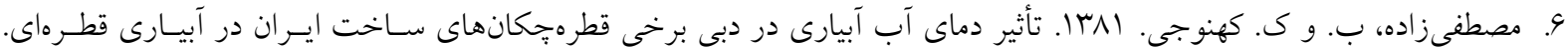

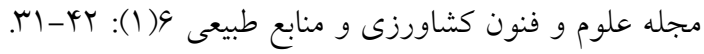

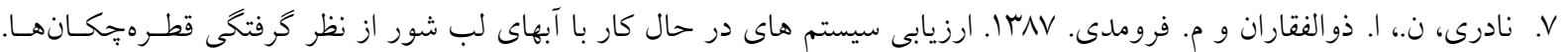

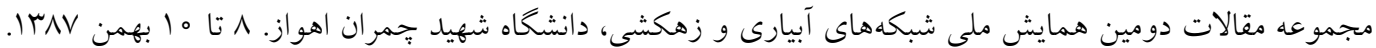

8. Boman, B. J. 1995. Effects of orifice size on microsprinkler clogging rates. J. Apple. Eng. Agric. 11(6): 839-843.

9. Bounoua, S., S. Tomas, J. Labille, B. Molle, J. Granier, P. Haldenwang and S. Nuur Izzati. 2016. Understanding physical clogging in drip irrigation: in situ, in-lab and numerical approaches. J. Irrig. Sci. 34(4): 327-342.

10. Bralts, V. F., I. P. Wu and H. M. Gitlin. 1981. Manufacturing variation and drip uniformity. Trans. ASAE. 24(1): 113-119.

11. Chieng, S. and A. Ghaemi. 2003. Uniformity in a microirrigation with partially clogged emitters. ASAE Paper No. 032097. ASAE, St. Joseph, MH.

12. Coelho, R. D. and R. S. Resende. 2001. Biological clogging of netafim's drippers and recovering process through chlorination impact treatment. ASAE Paper Number: 012231.

13. Gilbert R. G., F. S. Nakayama and D. A. Bucks. 1979. Trickle irrigation: Prevention of clogging. Trans. ASAE. 22: 514-519.

14. ISO 2003. Clogging Test Methods for Emitters. ISO Committee, ISO /TC 23/SC 18.

15. ISO 8486-1 .1997. Bond abrasives determination and designation of grain size distribution Macrogrits F4-F220.

16. Liu, H. and G. Huang .2009. Laboratory experiment on drip emitter clogging with fresh water and treated sewage effluent. J. Agric. Water Manage. 96: 745-756.

17. Merriam, J. L and J. keller. 1978. Farm Irrigation System Evaluation, a guide for Management. Utah state Univ. Utah, USA.

18. Nakayama, F. S. and D. A. Bucks. 1981. Emitter clogging effects on trickle irrigation uniformity. Trans. ASAE. 24(1): 77-80.

19. Niu. W., L. Liu. and X. Chen. 2012. Influence of fine particle size and concentration on the clogging of labyrinth emitters. J. Irrig. Sci. 10(2): 271-328. 
20. Pitts, D. J., D. Z. Haman and A. G. Smajstrla. 2003. Causes and prevention of emitter plugging in micro irrigation systems. BUL258, Gainesville, University of Florida, IFAS, Extension, 1-11.

21. Tajrishi, M. A., D. J. Hills and G. Tchobanoglous. 1994. Pretreatment of secondary effluent for drip irrigation. J. Irrig. Drain. Eng. 120(4): 716-731.

22. Wei, Q., G. Lu., J. Liu and Y. Shi. 2008a. Evaluation of emitter clogging in drip irrigation by two-phase flow simulation and laboratory experiments. J. Comput. Electron. Agric. 63: 294-303.

23. Wei, Q., Y. Shi, G. Lu, W. Dong and S. Huang. 2008b. Rapid Evaluations of Anticlogging Performance of Drip Emitters by Laboratorial Short-Cycle Tests. J. Irrig. Drain. Eng. 134: 298-304.

24. Wu, I. P., J. S. Feng and K. Yabusaki. 1989. Emitter spacing and uniformity of irrigation application. ASAE Paper No. 89-2080.

25. Yavuz, M., K. Demirel, O. Erken, E. Bahar and M. Deveciler. 2010. Emitter clogging and effects on drip irrigation system performances. Afr. J. Agric. Res. 5(7): 532-538. 


\title{
The Effect of Emitter Spacing on Physical Clogging of Drip Irrigation Tapes
}

\author{
C. Abdi and P. Fathi ${ }^{* 1}$ \\ (Received: Dec. 10-2014 ; Accepted: Nov. 22-2016)
}

\begin{abstract}
Drip irrigation is one of the new irrigation methods for optimum use of water resources and increase of irrigation efficiency. The emitters' clogging is the most important problem in these systems. The physical clogging is the most important factor in reducing the discharge and emission uniformity of emitters. The emitter position on the laterals and emitter spacing are the factors that affect the physical clogging rate of emitters. The objective of the present study is evaluating the effect of emitter spacing of drip irrigation tape on the physical clogging rate of emitters. For this purpose, a physical model of drip irrigation tape was designed and made at the laboratory. In this research, seamless and seamed irrigation tapes with emitter spacing equal to 10, 20 and 30 centimeters were used. Statistical analysis showed that emitters spacing have significant effect on clogging rate of emitters in seamless and seamed drip irrigation tapes. The results also indicated that seamless irrigation tapes with 30-centimeter emitters spacing, with clogging rate of 22 percent, have the least clogging. A comparison of clogging rate and uniformity coefficient of irrigation tape showed the higher performance of seamless irrigation tape in clogging condition.
\end{abstract}

Keywords: drip irrigation, tape, physical clogging, emitter spacing.

1. Dept. of Water Sci. Eng., Faculty of Agric., Univ. of Kurdistan, Kurdistan, Iran.

*: Corresponding Author, Email: fathip2000@yahoo.com 